\title{
Design, methods and demographic findings of the DEMINVALL survey: a population-based study of Dementia in Valladolid, Northwestern Spain
}

\author{
Miguel Angel Tola-Arribas*, María José Garea ${ }^{1}$, María Isabel Yugueros ${ }^{1}$, Fernando Ortega-Valín ', Ana Cerón², \\ Beatriz Fernández-Malvido ${ }^{3}$, Marta González-Touya ${ }^{4}$, Antonio San José ${ }^{4}$, Ana Botrán ${ }^{5}$ Vanessa Iglesias ${ }^{5}$, \\ Bárbara Díaz-Gómez ${ }^{4}$ and DEMINVALL study group
}

\begin{abstract}
Background: This article describes the rationale and design of a population-based survey of dementia in Valladolid (northwestern Spain). The main aim of the study was to assess the epidemiology of dementia and its subtypes. Prevalence of anosognosia in dementia patients, nutritional status, diet characteristics, and determinants of non-diagnosed dementia in the community were studied. The main sociodemographic, educational, and general health status characteristics of the study population are described.

Methods: Cross-over and cohort, population-based study. A two-phase door-to-door study was performed. Both urban and rural environments were included. In phase 1 (February 2009 - February 2010) 28 trained physicians examined a population of 2,989 subjects (age: $\geq 65$ years). The seven-minute screen neurocognitive battery was used. In phase 2 (May 2009 - May 2010) 4 neurologists, 1 geriatrician, and 3 neuropsychologists confirmed the diagnosis of dementia and subtype in patients screened positive by a structured neurological evaluation. Specific instruments to assess anosognosia, the nutritional status and diet characteristics were used. Of the initial sample, 2,170 subjects were evaluated ( $57 \%$ female, mean age $76.5 \pm 7.8,5.2 \%$ institutionalized), whose characteristics are described. 227 persons were excluded for various reasons. Among those eligible were 592 non-responders. The attrition bias of non-responders was lower in rural areas. 241 screened positive (11.1\%).

Discussion: The survey will explore some clinical, social and health related life-style variables of dementia. The population size and the diversification of social and educational backgrounds will contribute to a better knowledge of dementia in our environment.
\end{abstract}

Keywords: Dementia prevalence, Epidemiology, Undiagnosed dementia, Population-based survey, Seven-minute screen, Anosognosia, Nutritional assessment

\section{Background}

Demographic changes in world population during the next decades will cause an appreciable increase in the number of dementia patients [1]. Faced with the absence of disease-modifying treatments, control of dementia risk factors will be essential. A $10 \%$ reduction in diabetes, hypertension, obesity, smoking, depression, and cognitive or physical inactivity could potentially prevent

\footnotetext{
* Correspondence: mtola.nrl@gmail.com

'Department of Neurology, Hospital Universitario Río Hortega, Valladolid 47012, Spain

Full list of author information is available at the end of the article
}

more than 1 million cases of dementia worldwide [2]. More studies are required of the prevalence and incidence of dementia to chart the course of the disease, to confirm a cautious optimism in epidemiological trends [3], and to allow policymakers to plan the need for services.

In recent years several dementia prevalence surveys have been carried out in Spain [4-7] or are in progress [8] with considerable geographic variation that may be method-related [4]. A detailed analysis of the etiological subtypes, beyond Alzheimer's disease (AD) and vascular dementia, has been generally lacking. To our knowledge, 
the prevalence of anosognosia, which is very high in memory clinics [9], has never been evaluated in population studies. Other health related life style variables such as nutrition or factors associated with the lack of or the delay in the diagnosis of the disease in the community $[10,11]$ have barely been analyzed and thus justify new research in this field.

In 2008 we initiated the Dementia in Valladolid (DEMINVALL) survey in two geographically welldefined urban and rural populations in northwestern Spain aimed at describing (1) the prevalence and incidence of dementia and its subtypes, (2) the prevalence of anosognosia in dementia patients, (3) the characteristics of undiagnosed dementia in the community, and (4) the nutritional status and the daily consumption of micro and macronutrients. In this report we describe the design, methodology, and main general health, educational, and sociodemographic features of the study population.

\section{Methods/Design}

\section{Geographical area}

In January 2009, the population of the province of Valladolid was $532,575(18.2 \% \geq 65$ years $)$ with $6.7 \%$ of institutionalized persons. The city of Valladolid (189 $\mathrm{Km}$ northwest of Madrid) has a population of 317,864 , which has remained stable during last 10 years [12]. The main economic activities are manufacturing and service sector in urban areas and agriculture and viticulture in rural ones. Health care in Valladolid is organized into two separate areas, each with a university hospital that includes a neurology department and a geriatrics unit. Primary care is provided at community health centers and in doctors' offices in small rural areas.

\section{Study population}

The participants were sampled from the primary care registry of Social Security health card holders. In Spain, health care is free and universal, covering virtually the entire population. This selection method has various advantages: (1) it is continually updated; (2) provides personal data such as address, phone number and primary care physician; (3) provides access to medical record; (4) improved external validity.

In order to obtain a sample of all educational backgrounds and social classes in Valladolid, in addition to a good diversification of dementia risk factors, a mixed population -urban and rural- was selected. Communitydwelling and nursing home residents were included.

\section{Rural residential environment}

We selected the whole population aged 65 years and over of 11 municipalities of the "Montes Torozos" region (870 residents) in northwestern Valladolid $\left(338.9 \mathrm{Km}^{2}\right.$, population density $12.6 / \mathrm{km}^{2}$ ). In this rural area (Figure 1), primary care is available in two community health centers. The population is mainly blue-collar workers.

\section{Urban residential environment}

Residents aged 65 years and over from the districts of Campo Grande and Parquesol of the city of Valladolid $(6,183$ individuals) were selected. Each of these districts has a community health center. Due to the large population size, the survey was based on a $34.2 \%$, random, 5-

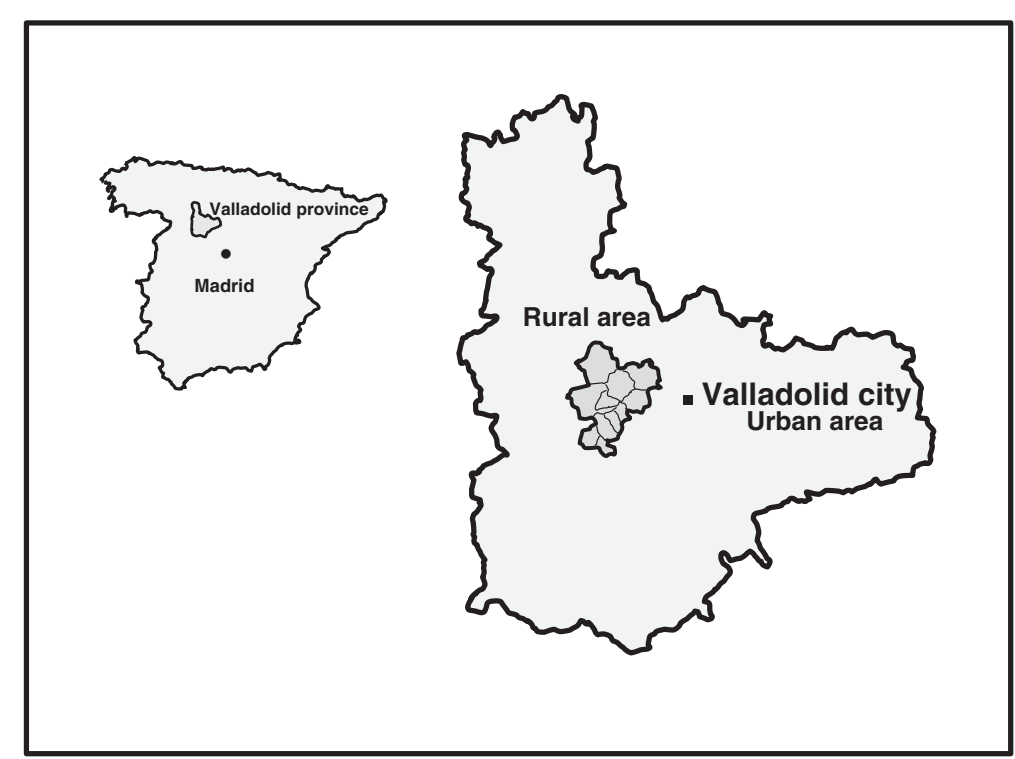

Figure 1 Location of the province of Valladolid and the rural area (municipalities of Villanubla, Peñaflor de Hornija, Wamba, Ciguñuela, Castrodeza, Torrelobatón, Matilla de los Caños, Robladillo, Villán de Tordesillas, Velilla and Velliza). 
year, age- and sex-stratified sample comprising 2,119 individuals. The size was calculated in order to provide an estimated $6.5 \%$ prevalence, $1 \%$ precision, $95 \%$ confidence interval, and $20 \%$ predicted losses. Both white and blue-collar workers are represented in this sample.

The eligibility criteria for this mixed population of 2,989 subjects were age 65 years and over on 1 February 2009 and at least 6 months residence in the previous year in the selected geographic areas. These areas were chosen for the following reasons: (1) existence of a computerized registry of the medical diagnoses of the participants; (2) the Rio Hortega University Hospital (RHUH) is the reference centre for the neurological and geriatric evaluation for both areas, with a single neurological team and a geriatrics unit; (3) a close relationship between the researchers and the primary care physicians; (4) proximity of the rural area to the RHUH.

\section{Study design}

DEMINVALL is a cross-over and cohort, population-based study. A cross-sectional, two-phase door-to-door design was adopted. Point prevalence was used as a disease frequency measure. The prevalence date was 1 February 2009. In order to be included in the prevalence numerator the patients had to be alive and had to meet the diagnostic criteria for dementia on or before this date.

The patients detected in the prevalence study have been followed up at regular intervals in the out-patient clinics of neurology and geriatrics in the RHUH. A dementia-free cohort was generated. The survivors of this cohort will be re-evaluated between October 2012 and May 2013 to describe the incidence of dementia and subtypes following a minimum observation period of three years from the prevalence date. A similar methodology will be used in two phases.

\section{Phase 1: screening}

In October 2008, a meeting of the researchers was held in which different clinical and epidemiological aspects of dementia were reviewed. Prior to the beginning of the survey a letter was sent to all selected subjects inviting them to participate and stating the absence of risk. In addition, the study was announced on the local radio, television, and press, and posters were placed in the health centers in order to better publicize the study.

\section{Field work team}

The participants were evaluated by 27 primary care physicians and one geriatrician from the largest nursing home. Five of the physicians coordinated the field work. All were trained to standardize the answers and to interpret the screening instruments. Whenever possible, the evaluation was carried out by the regular physicians.

\section{Screening protocol}

The initial interview was arranged by telephone and was held in the community health centers, physician's offices, or when necessary, in the participant's home or nursing home. At least five attempts to locate a potential participant within a period of three months were required in order to classify a subject as a non-located. Participants were asked to provide their medical reports and medications. Available medical records were also reviewed. The duration of the evaluation was 30 minutes and, when necessary, it was carried out in the presence of reliable informants. The evaluation period of the first phase was from February 2009 to February 2010.

Before administering the screening test, the eligibility criteria were confirmed and a structured questionnaire was filled out. Data concerning marital status, cohabitation, educational level and occupation history were collected. Social status was calculated according to an algorithm based on profession and level of training [13]. If a previous diagnosis of dementia existed, the type, onset date, main initial symptom, and date and level of care of diagnosis were evaluated. All those patients previously diagnosed with dementia were evaluated in the second phase of the study, regardless of whether or not the screening test results were negative or positive. In the absence of this diagnosis, existence of prior consultations for cognitive impairment, complaint symptoms and level of care in which they were held were evaluated. Also, information relative to the subjective health status, family history of dementia, cranial trauma, thyroid disease, and depression was collected. History of Parkinson's disease, essential tremor, stroke, ischemic heart disease, hypertension, and diabetes were evaluated. Duration of the illness, medications, and degree of control were specified. A history of tobacco and alcohol consumption (standard units of alcohol intake per week) was taken [14]. In addition, physical activity during the previous year was stratified according to intensity and to the number of days of exercise per week [15]. The blood pressure of those subjects without a history of hypertension was measured on two separate occasions. Finally, the body mass index was calculated.

\section{Screening instruments}

The 7 Minute Screen Neurocognitive Battery (7MS) was used [16]. This instrument evaluates temporal orientation, naming, delayed free- and cued-recall test of memory impairment, visuospatial organization, semantic processing and storage. A score of $<20$ points (8 percentile), regardless of age and cultural level, was considered positive. When it was not possible to perform the 7MS, the reasons were given and the short version of the Informant Questionnaire on Cognitive Decline in the Elderly (IQCODE) [17] was employed. 
A score of 57 and over was considered positive. In case of death after the prevalence date, collaboration of a close relative was sought, medical and sociocultural data were collected, and a Spanish version of the Kawas Dementia Questionnaire [18] was employed. This instrument provides a structured review of the general diagnostic criteria of dementia, AD, vascular dementia, and secondary dementia.

\section{Phase 2: Diagnostic confirmation Clinical research team}

The neurological assessment was carried out by four neurologists and one geriatrician, all experienced in dementia evaluation. Three neuropsychologists performed the neuropsychological evaluation. The coordinators of the first phase carried out the nutritional assessment, aided by the research unit of the RHUH and by a dietician. Two social workers conducted the social evaluation by telephone. A nurse took blood samples in the homes of those participants unable to travel. Genomic DNA was extracted from whole-blood samples and amplified by using polymerase chain reaction in the genetic department of the RHUH to determine ApoE genotype.

\section{Assessment protocol}

A comprehensive neurological assessment was offered to those participants with a positive screen or previous diagnosis of dementia. In addition, a randomly selected control group of 160 subjects was included $(8.3 \%$ of those who screened negative). The proportions of sex and age stratification with regard to those who screened positive were respected. The assessment was carried out in the out-patient clinics of neurology, geriatrics, and clinical psychology in the RHUH during two or three visits in the presence of a reliable informant. It was performed in the subject's home when necessary. The evaluation period was from May 2009 to May 2010. After revising the medical record and medications, a structured neurological examination was performed.

A brain imaging test (cranial CT or $1.5 \mathrm{~T} \mathrm{MRI)} \mathrm{was}$ suggested for all the subjects who screened positive. A single photon emission computed tomography imaging using [123] FP-CIT (DaTSCAN; GE Healthcare) was carried out on some patients with dementia and parkinsonism. Complete blood count, biochemical analysis, lipids, vitamin $\mathrm{B}_{12}$ levels, thyroid function, luetic serology, homocysteine, albumin, prealbumin, transferrin, and ApoE genotype were analyzed.

The neuropsychologic evaluation consisted of the use of the Cambridge Examination of Mental Disorders of the Elderly (CAMDEX) [19]. This instrument includes the necessary information to diagnose dementia and its subtypes, and includes an interview with an informant, the Blessed Scale, and an ischemic and depression scales. It also includes the Cambridge Cognitive Examination (CAMCOG) [20] that permits the scoring of the MiniMental State Examination (MMSE).

In addition, the protocol included the following instruments: (1) Rapid Disability Rating Scale-2 [21]; (2) Pittsburgh Sleep Quality Index [22]; (3) Zarit scale for assessing caregiver burden [23]; (4) Clinical Dementia Rating (CDR) [24]; (5) Global Deterioration Scale for assessment of primary degenerative dementia (GDS) [25], and (6) Functional Assessment Staging (FAST) [26]. In order to evaluate anosognosia, the Clinical Insight Rating Scale [27] and the Rating of Awareness Deficit [28], which were previously validated, were applied. The consumption of healthcare resources during the previous year was quantified by employing a questionnaire based on a national health survey of the Spanish National Institute of Statistics [29]. For the social evaluation, a structured interview of widespread use in Spain was employed [30].

For the nutritional evaluation, the Mini Nutritional Assessment Test was used [31]. In addition, a nutritional questionnaire was carried out in order to calculate the daily consumption of macro and micronutrients. To this end subjects were given a form in which they registered their consumption during a two-day period, one of the days falling on a weekend. The dietary data was managed by means of a personal computer, and the use of food scales and models to enhance portion size accuracy were incorporated. Records were reviewed by a registered dietitian and analyzed with a computer-based data evaluation system. National composition food tables were used as a reference [32].

\section{Diagnostic criteria}

Clinical diagnosis of dementia was established by agreement between the neurologist or geriatrician and the neuropsychologist responsible for each individual evaluation. Problematic cases and all the dementia questionnaires were reviewed by a second neurologist (M.A.T-A.).

The criteria of the Diagnostic and Statistical Manual of Mental Disorders (DSM-IV) [33] were applied for the diagnosis of dementia syndrome. In addition, the criteria of NINCDS-ADRDA for AD [34], the criteria of NINDS-AIREN for vascular dementia [35], the criteria of the DLB Consortium for dementia with Lewy bodies [36], the criteria for dementia associated with Parkinson's disease [37], and the criteria for frontotemporal lobar degeneration were applied [38]. AD with cerebrovascular disease was regarded as present in those patients that met the criteria of NINCDS-ADRDA for possible $\mathrm{AD}$ and who presented significant levels of small vessel ischemic changes, strategic lacunar infarcts, 


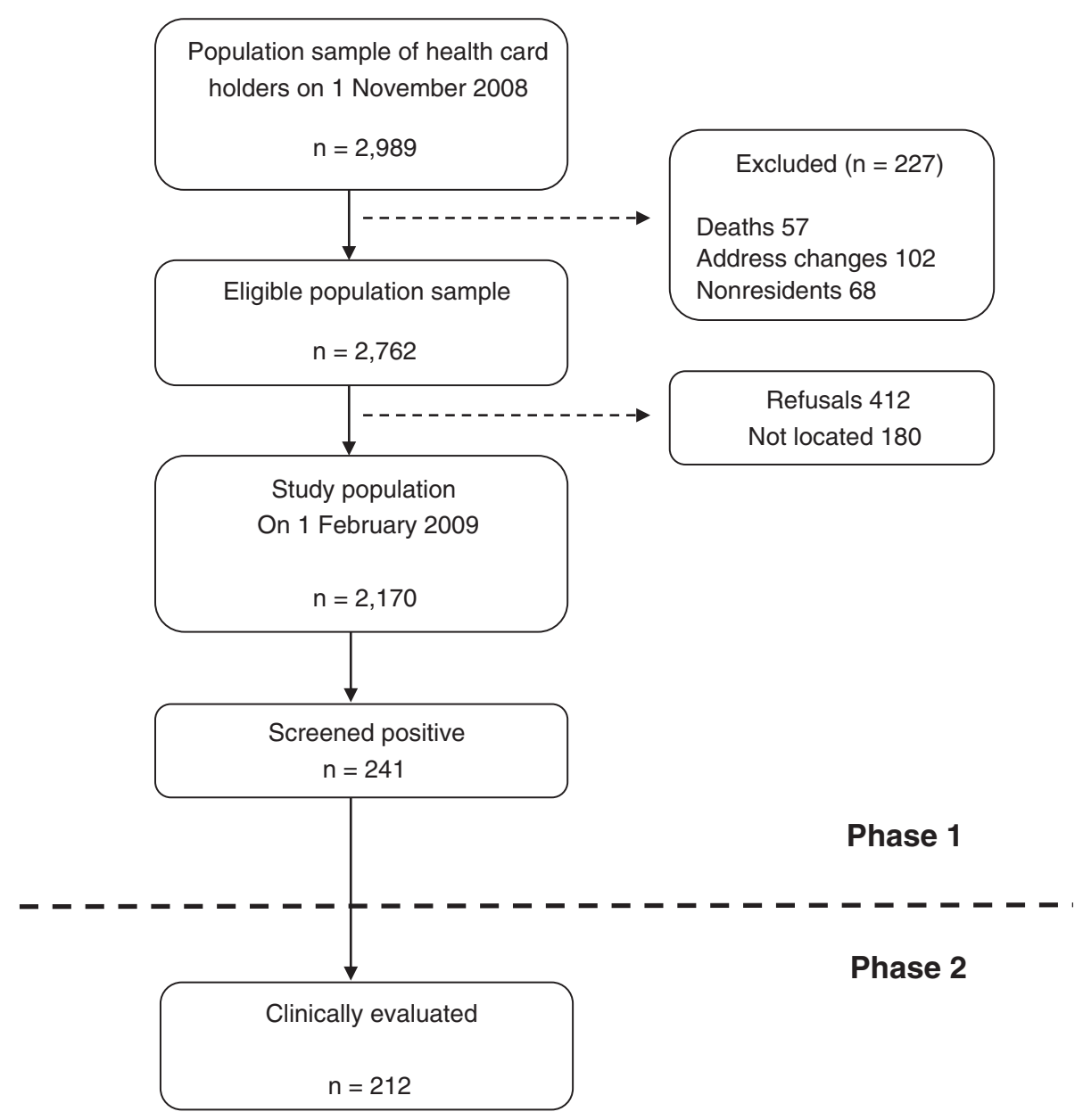

Figure 2 Flow chart showing the population selected and finally evaluated.

or large vessel infarcts on brain imaging and, in addition, who had a history of stroke or impaired neurological examination (focal deficit or gait disturbances) [39]. Secondary dementia was classified as having an identifiable or probable cause. When the clinical information was insufficient to reach an etiologic classification, undetermined dementia was diagnosed.

\section{Ethical aspects}

The survey was approved by the Ethics and Clinical Research Committee of the RHUH. All participants (or a relative when necessary) were asked to sign an informed consent. The database was inscribed in the Spanish Agency for Data Protection. Treatment and follow-up were offered to all patients with undetected dementia.

Table 1 Distribution of the evaluated population stratified by age, sex, and living environment

\begin{tabular}{|c|c|c|c|c|c|c|}
\hline \multirow[t]{2}{*}{ Age, years } & \multicolumn{2}{|c|}{ Urban population $(n=1,459)$} & \multicolumn{2}{|c|}{ Rural population $(n=711)$} & \multicolumn{2}{|c|}{ Total population $(n=2,170)$} \\
\hline & Men, $\mathrm{n}$ & Women, $\mathrm{n}$ & Men, $\mathrm{n}$ & Women, $\mathrm{n}$ & Men, $\mathrm{n}$ & Women, $\mathrm{n}$ \\
\hline $65-69$ & $162(27.7 \%)$ & $213(24.4 \%)$ & $91(26.1 \%)$ & $83(22.9 \%)$ & $253(27.1 \%)$ & $296(23.9 \%)$ \\
\hline $70-74$ & $154(26.3 \%)$ & $177(20.3 \%)$ & $84(24.1 \%)$ & $60(16.5 \%)$ & $238(25.5 \%)$ & $237(19.2 \%)$ \\
\hline $75-79$ & $124(21.2 \%)$ & $160(18.3 \%)$ & $79(22.7 \%)$ & $86(23.7 \%)$ & $203(21.8 \%)$ & $246(19.9 \%)$ \\
\hline $80-84$ & $83(14.2 \%)$ & $152(17.4 \%)$ & $61(17.5 \%)$ & $68(18.7 \%)$ & $144(15.4 \%)$ & $220(17.8 \%)$ \\
\hline $85-89$ & $42(7.2 \%)$ & $111(12.7 \%)$ & $26(7.5 \%)$ & $40(11.0 \%)$ & $68(7.3 \%)$ & $151(12.2 \%)$ \\
\hline$\geq 90$ & $20(3.4 \%)$ & $61(7.0 \%)$ & $7(2.0 \%)$ & $26(7.2 \%)$ & $27(2.9 \%)$ & $87(7.0 \%)$ \\
\hline Total & $585(100 \%)$ & 874 (100\%) & 348 (100\%) & $363(100 \%)$ & 933 (100\%) & $1,237(100 \%)$ \\
\hline
\end{tabular}

All percentages are column percentages. 
Table 2 Differences among analyzed and non-located subjects and refusals

\begin{tabular}{|c|c|c|c|}
\hline & Analyzed & Non-located & Refusals \\
\hline & $n=2,170$ & $n=180$ & $n=412$ \\
\hline Age (Mean $\pm S D$ ), years & $76.5 \pm 7.8$ & $76.6 \pm 7.8$ & $76.4 \pm 7.9$ \\
\hline Women (\%) & $57 \%$ & $55 \%$ & $61.2 \%$ \\
\hline Institutionalized (\%) & $5.2 \%$ & $2.2 \%$ & $3.2 \%$ \\
\hline Rural area (\%) & $32.8 \%$ & $16.7 \%^{1}$ & $14.6 \%^{2}$ \\
\hline
\end{tabular}

\begin{tabular}{llll}
\hline Age, years & & & \\
\hline $65-69$ & $25.3 \%$ & $28.9 \%$ & $27.4 \%$ \\
\hline $70-74$ & $21.8 \%$ & $18.3 \%$ & $19.2 \%$ \\
\hline $75-79$ & $20.7 \%$ & $16.7 \%$ & $22.1 \%$ \\
\hline $80-84$ & $16.8 \%$ & $22.2 \%$ & $16.0 \%$ \\
\hline $85-89$ & $10.1 \%$ & $8.9 \%$ & $9.5 \%$ \\
\hline$\geq 90$ & $5.3 \%$ & $5.0 \%$ & $5.8 \%$ \\
\hline 1
\end{tabular}

${ }_{1}^{1} p<0.001$. Difference between non-located and analyzed subjects.

$2 p<0.001$. Difference between refusals and analyzed subjects.

All other non-neurological processes detected were reported to the primary care physicians.

\section{Results}

Figure 2 shows a flow chart of participant attrition. 227 subjects $(7.6 \%)$ were excluded from the initial population for different reasons. Of the 2,762 eligible subjects, 180 (6.5\%) were non-located and 412 (14.9\%) refused to participate. The final population evaluated in the first phase was composed of 2,170 individuals; 241 (11.1\%) screened positive. Table 1 shows the distribution of the final population by age, sex and area of residence. Table 2 displays the differences between this population, nonlocated and non-collaborators. A smaller proportion of non-responders in rural areas was statistically significant. We obtained information about the educational level of 2,115 participants (97.5\%). Table 3 shows the distribution by age and gender. The sociodemographic data, occupation, general health, vascular risk factors and habits are displayed in Table 4, including the number of subjects analyzed in each case.

\section{Discussion}

From a methodological point of view, the DEMINVALL study presents some interesting differential characteristics with respect to other similar studies undertaken during the past few years [4-8]. First of all, the entire process of screening of the participants was carried out by trained medical personnel. In many cases this evaluation was performed by the subjects' habitual physicians. This fact contributed to a good participation in the urban area and to an optimum participation in the rural one. A similar approach was employed in the NEDISA [8] survey in Salamanca, Spain, in which a participation result of over $95 \%$ was obtained.

A second differential aspect is the choice of the screening instrument. In the majority of the populationbased surveys local versions of the MMSE have been employed [40]. The limitations of this test are well known, especially with regard to sensitivity and low positive predictive value in individuals with a low cultural level [41]. The 7MS was originally proposed as a screening test for $\mathrm{AD}$, although it usefulness in other types of dementias has been demonstrated [42]. Sensitivity and specificity of the 7MS are high and normative data concerning the Spanish population are available [43]. Due to its higher performance in the evaluation of episodic memory, it can contribute to the reduction of cost of screening in population studies, since it optimizes the detection of $\mathrm{AD}$ [44]. The main limitations are the administration time, which is normally over ten minutes, the requirement that the subject make a drawing of a clock, which limits its administration in patients with serious physical or sensorial defects, and the calculation of the score. Its usefulness has been placed in doubt in large epidemiological studies for these reasons [45]. Our initial hypothesis was that, despite these limitations, its greater efficacy allowed us to carry out a more reliable screening and, above all, a more efficient one (only $11.1 \%$ of the evaluated subjects were screened positive) with a lower consumption of healthcare resources in the second phase. The analysis of the false negatives in the control group and its positive predictive value will

Table 3 Educational level of DEMINVALL participants by age groups and gender

\begin{tabular}{|c|c|c|c|c|c|c|c|c|}
\hline \multirow[t]{2}{*}{ Age, years } & \multicolumn{2}{|c|}{ Illiterate(n = 25) } & \multicolumn{2}{|c|}{ Less than primary school $(n=451)$} & \multicolumn{2}{|c|}{ Primary school $(n=1,092)$} & \multicolumn{2}{|c|}{ Secondary school and higher $(n=547)$} \\
\hline & Men & Women & Men & Women & Men & Women & Men & Women \\
\hline $65-69$ & 2 & 2 & 41 & 49 & 104 & 165 & 104 & 79 \\
\hline $70-74$ & 0 & 2 & 31 & 43 & 129 & 139 & 78 & 47 \\
\hline $75-79$ & 1 & 6 & 46 & 64 & 93 & 124 & 61 & 47 \\
\hline $80-84$ & 1 & 6 & 39 & 59 & 69 & 107 & 28 & 41 \\
\hline 85-89 & 1 & 3 & 13 & 40 & 37 & 73 & 13 & 28 \\
\hline$\geq 90$ & 0 & 1 & 6 & 20 & 11 & 41 & 6 & 15 \\
\hline Total & 5 & 20 & 176 & 275 & 443 & 649 & 290 & 257 \\
\hline
\end{tabular}

Total years of schooling: $9.0 \pm 4.1$. 
Table 4 Characteristics of the evaluated population

\begin{tabular}{lc}
\hline \multicolumn{1}{c}{ Sociodemographic } \\
\hline Marital Status,\% $(\mathbf{n}=\mathbf{2 , 1 2 2})$ & 11.3 \\
\hline Single & 60.1 \\
\hline Married & 27 \\
\hline Widowed & 1.6 \\
\hline Separated/divorced & 18.1 \\
\hline Living arrangements,\% ( $\mathbf{= 2 , 1 7 0 )}$ & 45.7 \\
\hline Alone & 26.6 \\
\hline With spouse & 5.2 \\
\hline With relatives & 4.4 \\
\hline Institutionalized & 16.4 \\
\hline Others (including rotation among relatives) & 52.5 \\
\hline Social class, $\%$ ( $\mathbf{=} \mathbf{2 , 1 2 1 )}$ & 22.3 \\
\hline Low & 7.9 \\
\hline Medium-low & 0.9 \\
\hline Medium
\end{tabular}

\begin{tabular}{lc}
\hline Occupation/employment & \\
\hline Work history,\% $(\mathbf{n}=\mathbf{2 , 1 2 1 )}$ & 67.2 \\
\hline Blue-collar & 18.3 \\
\hline White-collar & 12.7 \\
\hline Services & 1.8 \\
\hline Never employed & \\
\hline Current occupation,\% ( $\mathbf{~ = ~ 2 , 1 1 6 )}$ & 54.7 \\
\hline Retired with no activity & 36.7 \\
\hline Active in habitual profession & 8.6
\end{tabular}

General data concerning health and habits

Subjective state of health, $\%(n=2,067)$

\begin{tabular}{lc}
\hline Bad or very bad & 7.4 \\
\hline Average & 29.1 \\
\hline Good or very good & 63.5 \\
\hline Body mass index $(\mathbf{n}=\mathbf{2 , 0 2 9 )}$ & $27.3 \pm 4.2$ \\
\hline Vascular risk factors, $\mathbf{( n = 2 , 1 7 0 )}$ & 15.8 \\
\hline Diabetes mellitus & 55.7 \\
\hline Hypertension & 10.7 \\
\hline Ischemic heart disease & 6.3 \\
\hline Stroke & 38.2 \\
\hline Ever-smoker
\end{tabular}

Alcohol consumption, $\%$ ( $n=2,124)$

\begin{tabular}{lc}
\hline Never drinker & 57.8 \\
\hline Active drinker & 34.7 \\
\hline Ex -drinker & 7.5 \\
\hline Daily consumption of alcohol (gr ethanol) & $15.8 \pm 1.5$ \\
\hline Active drinkers at risk & $7.3^{2}$ \\
\hline Physical exercise,\% $(\mathbf{n}=\mathbf{2 , 1 7 0 )}$ & 18.1 \\
\hline Sedentary &
\end{tabular}

Table 4 Characteristics of the evaluated population (Continued)

\begin{tabular}{ll}
\hline Low activity & 21.6 \\
\hline Moderate activity & 47.4 \\
\hline High activity & 12.9 \\
\hline${ }^{1}$ Daily consumption of ethanol over $30 \mathrm{gr}$. & \\
2 Percentage of active drinkers. &
\end{tabular}

permit its efficiency to be confirmed in a later analysis. In any case, the protocol established the application of the IQCODE, with a sensitivity similar to that of the MMSE [46], in those cases in which the application of the 7MS was not possible.

The survey included a specific evaluation of the characteristics of undiagnosed dementia in the community with the purpose of explaining the determinants of the delay or lack of identification of the disease in our environment. Among these, we analyzed the loss of insight, quite frequent in dementia, although it has never been evaluated in population-based studies. Finally, the nutritional evaluation of subjects with confirmed dementia and their comparison with the control group will provide valuable data concerning the influence of diet on dementia and of the latter on the nutritional state of the patients. In this sense, a favorable effect of the Mediterranean diet typical to our environment has been demonstrated [47].

A major limitation of the DEMINVALL survey, as in the majority of the observational studies with large populations, is the sample attrition bias. From the initial population, $7.6 \%$ of the selected subjects were excluded because they did not comply with the eligibility criteria, in part due to outdated health cards. Among the eligible subjects $21 \%$ were excluded from the denominator for the prevalence calculation because they were nonresponders. In the analysis of differences among the evaluated subjects and non-responders, only a lower participation in the urban area was statistically significant. The sample size of the latter, it should be pointed out, was calculated based on a predicted $20 \%$ loss; therefore, the impact bias will be lower.

In summary, we have presented the design and methodology of the DEMINVALL survey. It will allow us a more accurate view of the frequency of dementia in our environment and the reasons for diagnosis delay or the lack of detection. Therefore, we can contribute to a more efficient planning of health and social resources and to the implementation of plans that will facilitate early diagnosis, an aspect of maximum importance in the moment in which modifying treatments of the disease are available.

\section{Abbreviations}

AD: Alzheimer's disease; DEMINVALL: Dementia in Valladolid; RHUH: Rio Hortega University Hospital; 7MS: Seven-minute screen neurocognitive 
battery; IQCODE: Informant questionnaire on cognitive decline in the elderly; MMSE: Mini-mental state examination.

\section{Competing interests}

The authors declare that they have no competing interest.

\section{Authors' contributions}

Conception of the idea and design of the study: MAT-A, MJG, MIY, FO-V. Development of the protocol and general organization: MAT-A, BF-M, MG-T, $A S, A B, V I$ and $B D-G$. Field work organization and nutritional assessment: MGT, AS, AB, VI and BD-G. Neurological assessment: MAT-A, MJG, MIY, FO-V, AC. Neuropsycological assessment: BF-V. Writing of the manuscript: MAT-A, AC. All authors read and approved the final manuscript.

\section{Acknowledgments}

The authors would like to acknowledge the contribution of the following members of the DEMINVALL research group for their collaboration: Luz Alonso-Aldea, María Barranco, Aventina de la Cal, María José Castellanos, Miguel Angel Díez-García, Rosa García-Márquez, Amparo Gómez-Arranz, Pilar Gómez-Gómez, Tatiana González-Rebollar, Elisa Ibañes, Sofía Martín-Pelayo, Jesús Angel Moche, Patricia Montaut, Juan Pradera, Irene Repiso, Jorge Rubio, Teresa Salado, Natalia Santamarta, Ruperto Sanz, Raquel Talegón, Noelia Vicario and Juan Carlos Zamorano (primary care physicians); Lourdes Ausín (geriatrician); Belén Domenech and Ana Elúa (clinical psychologists); Rosa Lobo (genetics); Olatz Izaola (dietitian); Manuel González-Sagrado (research unit); Carlos Pinto and Isabel Hernández-Toribio (social workers); Miren Lorea García-Ugarte (nurse) and Javier Tola (DEMINVALL database).

\section{Funding}

The survey was funded by the Gerencia Regional de Salud de Castilla y León (Grant GRS/340/09) and by the Fundación General de la Universidad de Valladolid.

\section{Author details}

'Department of Neurology, Hospital Universitario Río Hortega, Valladolid 47012, Spain. ²Department of Geriatrics, Hospital Universitario Río Hortega, Valladolid, Spain. ${ }^{3}$ Department of Psychology, Hospital Universitario Río Hortega, Valladolid, Spain. ${ }^{4}$ Family Physician, Centro de Salud Campo Grande, Valladolid, Spain. ${ }^{5}$ Family Physician, Centro de Salud Parquesol, Valladolid, Spain.

Received: 8 April 2012 Accepted: 24 July 2012

Published: 30 August 2012

\section{References}

1. Prince M: The global prevalence of dementia. In World Alzheimer Report. Edited by Prince M, Jackson J. London: Alzheimer's Disease International; 2009:25-45.

2. Barnes DE, Yaffe $K$ : The projected effect of risk factor reduction on Alzheimer's disease prevalence. Lancet Neurol 2011, 10:819-828.

3. Rocca WA, Petersen RC, Knopman DS, Hebert LE, Evans DA, Hall KS, Gao S, Unverzagt FW, Langa KM, Larson EB, et al: Trends in the incidence and prevalence of Alzheimer's disease, dementia, and cognitive impairment in the United States. Alzheimers Dement 2011, 7:80-93.

4. De Pedro-Cuesta J, Virues-Ortega J, Vega S, Seijo-Martinez M, Saz P, Rodriguez F, Rodriguez-Laso A, Rene R, Heras SP DI, Mateos R, et al: Prevalence of dementia and major dementia subtypes in Spanish populations: a reanalysis of dementia prevalence surveys, 1990-2008. BMC Neurol 2009, 9:55.

5. Virues-Ortega J, de Pedro-Cuesta J, Vega S, Seijo-Martinez M, Saz P, Rodriguez F, Rodriguez-Laso A, Rene R, de Las Heras SP, Mateos R, et al: Prevalence and European comparison of dementia in a $>/=75$-year-old composite population in Spain. Acta Neurol Scand 2010, 123:316-324.

6. Gavrila D, Antunez C, Tormo MJ, Carles R, Garcia Santos JM, Parrilla G, Fortuna L, Jimenez J, Salmeron D, Navarro C: Prevalence of dementia and cognitive impairment in Southeastern Spain: the Ariadna study. Acta Neurol Scand 2009, 120:300-307.

7. Rodriguez-Sanchez E, Mora-Simon S, Patino-Alonso MC, Garcia-Garcia R, Escribano-Hernandez A, Garcia-Ortiz L, Perea-Bartolome MV, Gomez-Marcos MA: Prevalence of cognitive impairment in individuals aged over 65 in an urban area: DERIVA study. BMC Neurol

2011, 11:147.

8. Cacho J, Benito-Leon J, Louis ED: Methods and design of the baseline survey of the neurological disorders in Salamanca (NEDISA) cohort: a population-based study in Central-Western Spain. Neuroepidemiology 2011, 36:62-68.

9. Lopez OL, Becker JT, Somsak D, Dew MA, DeKosky ST: Awareness of cognitive deficits and anosognosia in probable Alzheimer's disease. Eur Neurol 1994, 34:277-282.

10. Connolly A, Gaehl E, Martin H, Morris J, Purandare N: Underdiagnosis of dementia in primary care: Variations in the observed prevalence and comparisons to the expected prevalence. Aging Ment Health 2011, 15:978-984.

11. Bradford A, Kunik ME, Schulz P, Williams SP, Singh H: Missed and delayed diagnosis of dementia in primary care: prevalence and contributing factors. Alzheimer Dis Assoc Disord 2009,

23:306-314.

12. Spanish Population and demographic census. http://www.ine.es/inebmenu/ mnu_cifraspob.htm.

13. Rojo Perez F, Fernandez-Mayoralas G, Pozo-Rivera F, Rojo-Abuin J: Ageing in place: predictors of the residencial satisfaction of elderly. Soc Indic Res 2001, 54:173-208.

14. Babor T, Biddle-Higgins J, Saunders J, Monteiro M: AUDIT: The Alcohol Use Disorders Identification Test: Guidelines for Use in Primary Health Care. Geneva: World Health Organization; 2001.

15. Laurin D, Verreault R, Lindsay J, MacPherson K, Rockwood K: Physical activity and risk of cognitive impairment and dementia in elderly persons. Arch Neurol 2001, 58:498-504.

16. Solomon PR, Hirschoff A, Kelly B, Relin M, Brush M, DeVeaux RD, Pendlebury WW: A 7 minute neurocognitive screening battery highly sensitive to Alzheimer's disease. Arch Neurol 1998, 55:349-355.

17. Jorm AF, Korten AE: Assessment of cognitive decline in the elderly by informant interview. Br J Psychiatry 1988, 152:209-213.

18. Kawas C, Segal J, Stewart WF, Corrada M, Thal L: A validation study of the Dementia Questionnaire. Arch Neuro/ 1994, 51:901-906.

19. Roth M, Tym E, Mountjoy CQ, Huppert FA, Hendrie H, Verma S, Goddard R: CAMDEX. A standardised instrument for the diagnosis of mental disorder in the elderly with special reference to the early detection of dementia. Br J Psychiatry 1986, 149:698-709.

20. Huppert FA, Brayne C, Gill C, Paykel ES, Beardsall L: CAMCOG, a concise neuropsychological test to assist dementia diagnosis: socio-demographic determinants in an elderly population sample. Br J Clin Psychol 1995, 34:529-541.

21. Linn MW, Linn BS: The rapid disability rating scale-2. J Am Geriatr Soc 1982, 30:378-382.

22. Buysse DJ, Reynolds CF 3rd, Monk TH, Berman SR, Kupfer DJ: The Pittsburgh Sleep Quality Index: a new instrument for psychiatric practice and research. Psychiatry Res 1989, 28:193-213.

23. Zarit SH, Reever KE, Bach-Peterson J: Relatives of the impaired elderly: correlates of feelings of burden. Gerontologist 1980, 20:649-655.

24. Hughes CP, Berg L, Danziger WL, Coben LA, Martin RL: A new clinical scale for the staging of dementia. Br J Psychiatry 1982, 140:566-572.

25. Reisberg B, Ferris SH, de Leon MJ, Crook T: The Global Deterioration Scale for assessment of primary degenerative dementia. Am J Psychiatry 1982, 139:1136-1139.

26. Reisberg B: Functional assessment staging (FAST). Psychopharmacol Bull 1988, 24:653-659.

27. Ott BR, Fogel BS: Measurement of depression in dementia: self vs clinician rating. Int J Geriatr Psychiatry 1992, 7:899-904

28. Verhey FR, Ponds RW, Rozendaal N, Jolles J: Depression, insight, and personality changes in Alzheimer's disease and vascular dementia. J Geriatr Psychiatry Neurol 1995, 8:23-27.

29. Spanish National Health Survey. http://www.ine.es/inebmenu/mnu_salud.htm.

30. Garcia Gonzalez JV, Diaz Palacios E, Salamea Garcia A, Cabrera Gonzalez D, Menendez Caicoya A, Fernandez Sanchez A, Acebal Garcia V: An evaluation 
of the feasibility and validity of a scale of social assessment of the elderly. Aten Primaria 1999, 23:434-440.

31. Vellas B, Guigoz Y, Garry PJ, Nourhashemi F, Bennahum D, Lauque $S$, Albarede JL: The Mini Nutritional Assessment (MNA) and its use in grading the nutritional state of elderly patients. Nutrition 1999, 15:116-122.

32. Mataix J, Mañas M, Llopis J, Martínez De Victoria E: Tablas de composición de alimentos españoles. Granada: University of Granada; 2003.

33. American Psychiatric Association: Diagnostic and Statistical Manual of Mental Disorders. 4th edition. Washington DC: American Psychiatric Association; 1994:133-155.

34. McKhann G, Drachman D, Folstein M, Katzman R, Price D, Stadlan EM: Clinical diagnosis of Alzheimer's disease: report of the NINCDS-ADRDA Work Group under the auspices of Department of Health and Human Services Task Force on Alzheimer's Disease. Neurology 1984, 34:939-944.

35. Roman GC, Tatemichi TK, Erkinjuntti T, Cummings JL, Masdeu JC, Garcia JH, Amaducci L, Orgogozo JM, Brun A, Hofman A, et al: Vascular dementia: diagnostic criteria for research studies. Report of the NINDS-AIREN International Workshop. Neurology 1993, 43:250-260

36. McKeith IG: Consensus guidelines for the clinical and pathologic diagnosis of dementia with Lewy bodies (DLB): report of the Consortium on DLB International Workshop. J Alzheimers Dis 2006, 9(Suppl 3):417-423.

37. Emre M, Aarsland D, Brown R, Burn DJ, Duyckaerts C, Mizuno Y, Broe GA Cummings J, Dickson DW, Gauthier S, et al: Clinical diagnostic criteria for dementia associated with Parkinson's disease. Mov Disord 2007, 22:1689-1707.

38. Neary D, Snowden JS, Gustafson L, Passant U, Stuss D, Black S, Freedman M, Kertesz A, Robert PH, Albert M, et al: Frontotemporal lobar degeneration: a consensus on clinical diagnostic criteria. Neurology 1998, 51:1546-1554

39. Dubois B, Feldman HH, Jacova C, Cummings JL, Dekosky ST, BarbergerGateau P, Delacourte A, Frisoni G, Fox NC, Galasko D, et al: Revising the definition of Alzheimer's disease: a new lexicon. Lancet Neurol 2010, 9:1118-1127.

40. O'Connor DW: Prevalence and incidence of dementia. In Dementia. 4th edition. Edited by Ames DBA, OBrien J. London: Hodder Arnold; 2010:22-30.

41. Strauss E: Mini-Mental State Examination. In A compendium of neuropsychological test: administration, norms and commentary. Edited by Strauss E, Sherman EM, Spreen O. Oxford: Oxford University Press; 2006:168-189.

42. Meulen EF, Schmand B, van Campen JP, de Koning SJ, Ponds RW, Scheltens $P$, Verhey FR: The seven minute screen: a neurocognitive screening test highly sensitive to various types of dementia. J Neurol Neurosurg Psychiatry 2004, 75:700-705.

43. Del Ser Quijano T, Sanchez Sanchez F, de Yebenes MJ G, Otero Puime A Zunzunegui MV, Munoz DG: Spanish version of the 7 Minute screening neurocognitive battery. Normative data of an elderly population sample over 70. Neurologia 2004, 19:344-358

44. Evans DA, Grodstein F, Loewenstein D, Kaye J, Weintraub S: Reducing case ascertainment costs in U.S. population studies of Alzheimer's disease, dementia, and cognitive impairment-Part 2. Alzheimers Dement 2011, 7:110-123.

45. Del Ser T, Sanchez-Sanchez F, de Yebenes MJ G, Otero A, Munoz DG: Validation of the seven-minute screen neurocognitive battery for the diagnosis of dementia in a Spanish population-based sample. Dement Geriatr Cogn Disord 2006, 22:454-464.

46. Morales-Gonzalez JM, Gonzalez-Montalvo Jl, del Ser Quijano T, Bermejo-Pareja F: Estudio de validación del S-IQCODE: la versión española del Informant Questionnaire on Cognitive Decline in the Elderly. Arch Neurobiol 1992, 55:262-266.

47. Scarmeas N, Stern Y, Tang MX, Mayeux R, Luchsinger JA: Mediterranean diet and risk for Alzheimer's disease. Ann Neurol 2006, 59:912-921.

doi:10.1186/1471-2377-12-86

Cite this article as: Tola-Arribas et al: Design, methods and demographic findings of the DEMINVALL survey: a population-based study of Dementia in Valladolid, Northwestern Spain. BMC Neurology 2012 12:86.

\section{Submit your next manuscript to BioMed Central and take full advantage of:}

- Convenient online submission

- Thorough peer review

- No space constraints or color figure charges

- Immediate publication on acceptance

- Inclusion in PubMed, CAS, Scopus and Google Scholar

- Research which is freely available for redistribution 